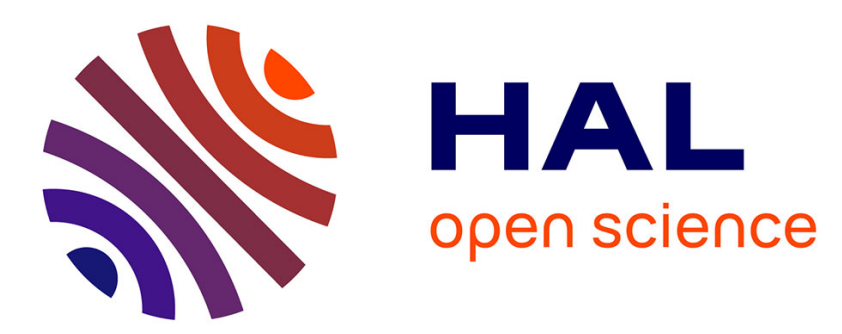

\title{
A physico-chemical approach of polyanion-polycation interactions aimed at better understanding the in vivo behaviour of polyelectrolyte-based drug delivery and gene transfection.
}

\author{
Laurent Leclercq, Mahfoud Boustta, Michel Vert
}

\section{To cite this version:}

Laurent Leclercq, Mahfoud Boustta, Michel Vert. A physico-chemical approach of polyanionpolycation interactions aimed at better understanding the in vivo behaviour of polyelectrolytebased drug delivery and gene transfection.. Journal of Drug Targeting, 2003, 11 (3), pp.129-38. 10.1080/1061186031000150287 . hal-00626858

\section{HAL Id: hal-00626858 https://hal.science/hal-00626858}

Submitted on 27 Sep 2011

HAL is a multi-disciplinary open access archive for the deposit and dissemination of scientific research documents, whether they are published or not. The documents may come from teaching and research institutions in France or abroad, or from public or private research centers.
L'archive ouverte pluridisciplinaire HAL, est destinée au dépôt et à la diffusion de documents scientifiques de niveau recherche, publiés ou non, émanant des établissements d'enseignement et de recherche français ou étrangers, des laboratoires publics ou privés. 


\title{
A Physico-chemical Approach of Polyanion-Polycation Interactions Aimed at Better Understanding the In Vivo Behaviour of Polyelectrolyte-based Drug Delivery and Gene Transfection
}

\author{
LAURENT LECLERCQ*, MAHFOUD BOUSTTA and MICHEL VERT
}

Research Center for Artificial Biopolymers, UMR CNRS 5473, University of Montpellier 1, Faculty of Pharmacy, 15 avenue Charles Flahault, BP 14491-34093, Montpellier Cedex 5, France

(Received ???)

\begin{abstract}
Polyanions and polycations are known to interact electrostatically and form soluble or insoluble polyelectrolyte complexes. Body fluids, blood and cells are composed of many polyelectrolytic systems such as proteins, glycoproteins, poly(glycosamino glycane)s, polynucleotides, etc. under physiological conditions. Nowadays synthetic polyelectrolytes are proposed as carriers of bioactive compounds, such as drugs and genes, and are thus to be injected into body fluids. For the sake of better understanding the complex behaviour of such artificial polyelectrolytic systems in the pool of natural polyelectrolytes forming living systems, interactions of bi- and multi-components mixtures of synthetic polyanions with the same synthetic polycation, namely poly[(dimethylaminoethyl) methacrylate], $\mathrm{HCl}$, were investigated under the conditions imposed by physiological media, namely $\mathrm{pH}=7.4$, ionic strength $\mu=0.15$ and $T=37^{\circ} \mathrm{C}$. The selected artificial polyanions were the sodium salts of poly(acrylic acid), poly(methacrylic acid), poly(L-lysine citramide) and poly(styrene sulfonic acid) which have different acid strength, charge density and ionogenic group. The influence of ionic strength and $\mathrm{pH}$ on complex formation and stability was investigated by turbidimetry at $\lambda=520 \mathrm{~nm}$. Phase separation occurred regardless of ionic strength in the case of sodium polystyrene sulfonate. For the other polyanions, redissolution was observed at critical $\mathrm{NaCl}$ concentrations much higher than the physiological ionic strength. In the case of mixtures of two or three polyanions with the polycation, the complex formation appeared polyanion-selective at physiological ionic strength. Data are discussed with regard to phenomena that can occur in vivo.
\end{abstract}

Keywords: Polyelectrolytes; Polyelectrolytic complexes; Polymeric drug carriers; Gene transfection; Polyanions; Polycations

\section{INTRODUCTION}

The investigation of the physicochemical behaviours of polyelectrolytes of natural origin such as proteins, glycoproteins and polynucleotides started many decades ago (Fuoss and Sadek, 1949; Michaels and Miekka, 1961; Morawetz, 1965; Rembaum and Sélégny, 1975). Almost at the same time, the study of synthetic polyelectrolytes was initiated and it is now well known that polyions of opposite electrostatic charges interact to form interpolyelectrolyte complexes or IPECs. The complexation is primarily based on Coulombic forces (Kossel, 1896), although other spaceoriented intermacromolecular interactions, such as hydrogen bonding and non-oriented ones, such as hydrophobic and/or charge-transfer and/or van der Waals interactions, can also play a critical role (Nakajima, 1980; Tsuchida, 1980; 1994; Bekturov and Bimendina, 1981; Tsuchida, 1982; Kabanov and Zezin, 1984; Philipp et al., 1989). The formation and the properties of IPECs in aqueous media are determined by a number of factors, e.g. nature, position of ionic groups, size, charge density and concentration of macromolecules, proportion of opposite charges, physicochemical environment (e.g. ionic strength, $\mathrm{pH}$, temperature, etc.) as well as the method of preparation, in particular the order and rate of solutions mixing (Hara and Nakajima, 1978; Nakajima, 1980; Tsuchida, 1980; 1994; Bekturov and Bimendina, 1981;Tsuchida and Abe, 1982; Kabanov and Zezin, 1984; Philipp et al., 1989; Kötz et al., 1996). In literature, less

*Corresponding author. Tel.: +33-467-418-260. Fax: +33-467-520-898. E-mail: leclercq@pharma.univ-montp1.fr 
attention has been paid to IPECs compared with other polymeric blends, primarily because of the difficulty to precisely characterize insoluble solid systems whose formation is generally far from thermodynamic equilibrium (Nakajima, 1980; Tsuchida, 1980; 1994; Bekturov and Bimendina, 1981; Tsuchida and Abe, 1982; Philipp et al., 1989; Kabanov, 1994). In the recent years, interactions between positively and negatively charged polyelectrolytic systems received renewed attention thanks to the development of fields like drug transport and gene transfection. Indeed synthetic polyelectrolytes can be used as polymeric drug carriers (Vert, 1986). Presently, polycations are investigated for gene or DNA condensation and transfection (Kabanov et al., 1985; Behr, 1994; Kabanov, 1994; Blessing et al., 2001). However, such applications imply injection of polyelectrolytic systems or IPECs into blood where electrostatically patched proteins and cell surfaces are present and thus can interfere under defined physicochemical conditions imposed by the living medium. Moreover, most polycations are hemotoxic. It has been recently shown that the toxicity of polycations can be assigned to interactions with negatively charged red blood cells and proteins, the in vitro effects including cell aggregation and hemolysis (Moreau et al., 2000a, b). These interactions and their effects have been shown to depend on the type of cationic charges, on the polycation concentration and even on the order of addition of the interacting species (Moreau, 2002).

One of the striking features of body fluids, especially blood, is the presence of a great number of polyelectrolytic macromolecules that are in close contact with no dramatic phase separation. This situation is likely to be locally perturbed when foreign polyelectrolytes or IPECs are introduced. So far, literature has been rather silent on such effects, probably because of the complexity of the behaviour of charged polymers in contact with body fluids. Recently, it was shown that the inhibitory effects of glycosaminoglycans on gene transfer cannot be explained, in most cases, by a decreased cellular uptake of DNA-cationic species complexes (Ruponen et al., 2001). The authors suggested that glycosaminoglycans may bind to the cationic carrier or to the surface of positively charged IPECs. They also proposed that glycosaminoglycans may replace DNA in the initial complex resulting in the uptake of the anionic polysaccharide into the cells instead of DNA. Several years ago, Kabanov described exchange reactions, e.g. $\mathrm{PA}_{1}-\mathrm{PC}+\mathrm{PA}_{2} \rightleftarrows \mathrm{PA}_{2}-$ $\mathrm{PC}+\mathrm{PA}_{1}$ where $\mathrm{PA}_{1}$ and $\mathrm{PA}_{2}$ are two different polyanions and $\mathrm{PC}$ is a polycation. The work involved synthetic polyelectrolytes (Kabanov et al., 1985; Izumrudov et al., 1995) and DNA (Izumrudov et al., 1995). The authors studied the formation and stability of corresponding IPECs as a function of various factors, namely nature of the external salt, salt concentration and average degree of polymerization $\left(D_{w}\right)$. They found that these three factors played an important role on polyanion-polycation exchanges, even in the case of biopolymers (Kabanov, 1994). However, neither the physical chemistry of such complex mixtures nor the effects of the slight changes that can occur locally in some body compartments, have been investigated deeply under the conditions imposed by the human body.

In this first article, we wish to report the results of a preliminary study involving bi- or multi-component mixtures of different synthetic polyanions with the same synthetic polycation under conditions that are typical of body fluids, namely temperature $T=37^{\circ} \mathrm{C}$, $\mathrm{pH}=7.4$ (blood) or 4.5 (lysosomal vesicles) and ionic strength $\mu=0.15$ in $\mathrm{NaCl}$. In order to support the discussion on the effects of ionic strength on complex formation and stability, investigations were also carried out at various salt concentrations. The selected polyanions were the sodium salts of poly(acrylic acid), (NaPAA), poly(methacrylic acid), (NaPMA), poly(L-lysine citramide), (NaPLCA), poly(L-lysine citramide imide), (NaPLCAI) and poly(styrenesulfonic acid), (NaPSS). The polycation was the hydrochloride salt of poly(dimethylaminoethyl methacrylate), (PDMAEMA, $\mathrm{HCl}$ ) (Scheme 1). Although IPEC formation is known to be dependent on the molecular weight of the involved polyelectrolytes (Kabanov et al., 1985; Izumrudov et al., 1988), in the present work the effect of molecular weights was considered as negligible with respect to electrostatic effects between polyanions of different chemical structures.

\section{MATERIALS AND METHODS}

\section{Materials}

Poly(dimethylaminoethyl methacrylate hydrochloride) $\left(\mathrm{M}_{\mathrm{W}}=100,000 \mathrm{~g} \cdot \mathrm{mol}^{-1}, \mathrm{DP}_{\mathrm{W}}=515\right)$ was purchased from COATEX. Sodium poly(acrylate) $\left(\mathrm{M}_{\mathrm{w}}=20,000\right.$ $\mathrm{g} . \mathrm{mol}^{-1}, \mathrm{DP}_{\mathrm{W}}=213$ ) and sodium poly(styrene sulfonate $)\left(\mathrm{M}_{\mathrm{w}}=70,000 \mathrm{~g} \cdot \mathrm{mol}^{-1}, \mathrm{DP}_{\mathrm{W}}=340\right)$ were supplied by FLUKA and ACROS, respectively. Commercial PAA polymers are usually more or less branched because of radical transfers to growing chains during the polymerization process. The presence of branches was not taken into account in this study. Sodium poly(methacrylate) $\left(\mathrm{M}_{\mathrm{w}}=50,000 \mathrm{~g} \cdot \mathrm{mol}^{-1}, \mathrm{DP}_{\mathrm{W}}=463\right)$ was prepared by radical polymerization of methacrylic acid from ALDRICH, using $\mathrm{K}_{2} \mathrm{~S}_{2} \mathrm{O}_{8}$ at $\mathrm{pH} \sim 10$ as the initiator (Bovey, 1963). Poly(L-lysine citramide imide) and poly(L-lysine citramide $) \quad\left(\mathrm{M}_{\mathrm{w}}=20,000 \mathrm{~g} \cdot \mathrm{mol}^{-1}\right.$, $\mathrm{DP}_{\mathrm{W}}=65$ and58, respectively) were synthesized in our laboratory as previously reported (Boustta et al., 1991).

$\mathrm{NaCl}$ was purchased from MERCK and used as received. Water was purified and de-ionized using a Milli-RO system from Millipore.

\section{Preparation of Polyelectrolyte Complexes}

Typically, a PDMAEMA, $\mathrm{HCl}$ solution at the desired $\mathrm{NaCl}$ concentration was added dropwise to a stirred dilute solution of Na-polyanion at the same $\mathrm{NaCl}$ concentration. 


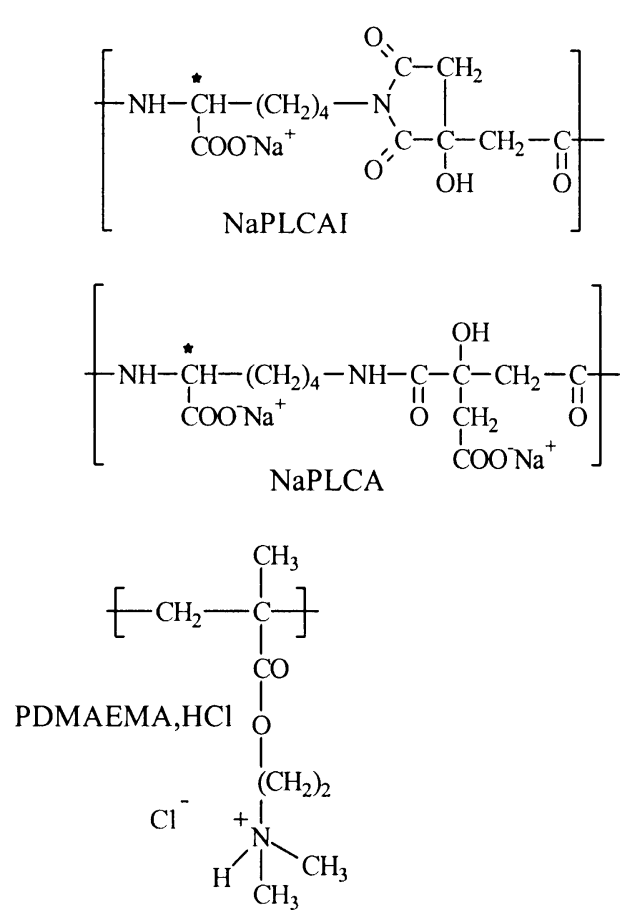




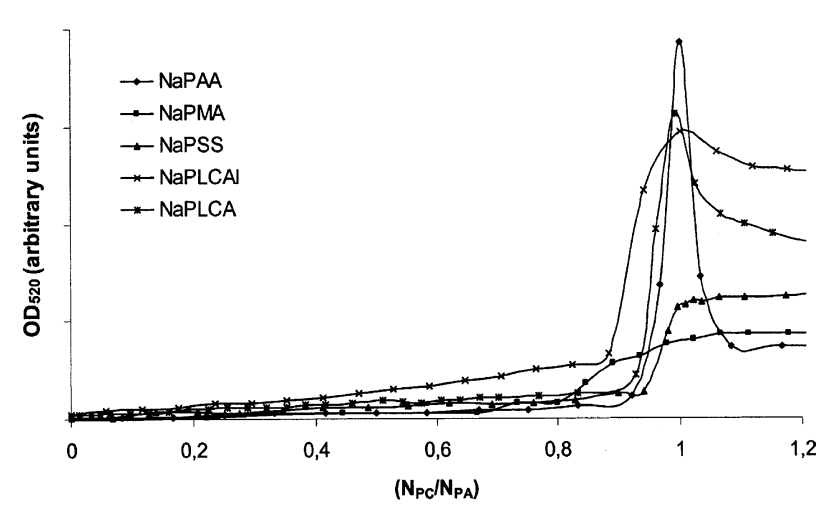

FIGURE 1 Evolution of $\mathrm{OD}_{520}$ for various polyanion-PDMAEMA systems as a function of the $\mathrm{N}_{\mathrm{PC}} / \mathrm{N}_{\mathrm{PA}}$ cation/anion ratio ([Polyanion] $=$ 8.0.10 $\left.0^{-4} \mathrm{~mol} .1^{-1}\right)$.

Under these conditions, all the investigated mixtures generated a precipitate when $\mathrm{N}_{\mathrm{PC}} / \mathrm{N}_{\mathrm{PA}}$ (the positive/ negative charge ratio, where $\mathrm{N}_{\mathrm{PC}}$ and $\mathrm{N}_{\mathrm{PA}}$ stand for the concentrations in cationic and anionic species born by the polyelectrolytes respectively) was equal to one. Figure 1 shows the variation of $\mathrm{OD}_{520}$ for the different polyanionPDMAEMA systems as a function of $\mathrm{N}_{\text {PC }} / \mathrm{N}_{\text {PA }}$. At low $\mathrm{N}_{\mathrm{PC}} / \mathrm{N}_{\mathrm{PA}}, \mathrm{OD}_{520}$ raised linearly and reproducibly up to a critical value, beyond which $\mathrm{OD}_{520}$ increased dramatically to reach a maximum at $\mathrm{N}_{\mathrm{PC}} / \mathrm{N}_{\mathrm{PA}}=1$. For NaPLCA, NaPLCAI and NaPAA having comparable average molar masses in the range of $20,000 \mathrm{~g} \cdot \mathrm{mol}^{-1}$, slope changes were observed at $\mathrm{N}_{\mathrm{PC}} / \mathrm{N}_{\mathrm{PA}}=0.92,0.94$ and 0.84 respectively. It is worth noting that NaPLCA and NaPLCAI molecules bore hydroxyl pendent groups. Presumably, these hydroxyl groups provided extra hydrophilicity that can explain the delayed phase separation. For NaPSS and NaPMA that had greater molar masses, the critical $\mathrm{N}_{\mathrm{PC}} / \mathrm{N}_{\mathrm{PA}}$ value was 0.90 for NaPSS and 0.80 for NaPMA. Below the critical $\mathrm{N}_{P C} / \mathrm{N}_{P A}$ value, $\mathrm{OD}_{520}$ stayed very low, as in the case of the pure solvent, in agreement with the formation of nanodispersed IPECs.

Similar features were observed when the initial polyanion concentration was lower than $10^{-3}$ mol.1 $1^{-1}$. Above, turbidity was detected even at very low $\mathrm{N}_{\mathrm{PC}} / \mathrm{N}_{\mathrm{PA}}$, the higher the concentration, the greater the increase of $\mathrm{OD}_{520}$ with $\mathrm{N}_{\mathrm{PC}} / \mathrm{N}_{\mathrm{PA}}$. This trend was assigned to increases of particle size and compactness as well documented in literature (Tsuchida, 1980; 1994; Bekturov and Bimendina, 1981; Tsuchida and Abe, 1982; Philipp et al., 1989).

\section{In Salt-containing Water}

\section{COMPLEX FORMATION}

The influence of ionic strength on IPEC formation is known to depend on both the nature and the molecular weight of polyions (Kabanov and Kabanov, 1995; Izumrudov et al., 1988). In the present study, the number of cationic charges needed to reach maximal turbidity

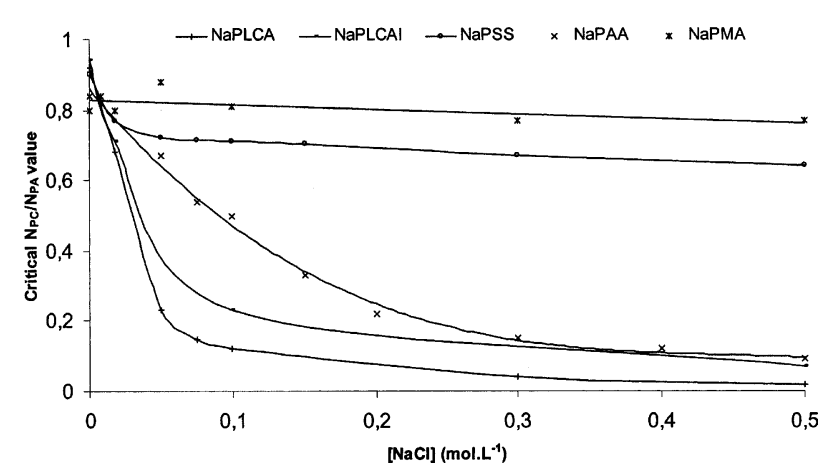

FIGURE 2 Variation of the critical $\mathrm{N}_{\mathrm{PC}} / \mathrm{N}_{\mathrm{PA}}$ value of different polyanions above which $\mathrm{OD}_{520}$ increased dramatically as a function of the salt concentration ([Polyanion] $=8 \cdot 0 \cdot 10^{-4} \mathrm{~mol} .1^{-1}$ ).

decreased dramatically as the salt concentration increased, the residual electrostatic charges that prevented aggregation being screened by small ions as it is well known. Figure 2 shows the ionic strength-dependence of critical $\mathrm{N}_{\mathrm{PC}} / \mathrm{N}_{\mathrm{PA}}$ values for different $8 \cdot 0 \cdot 10^{-4} \mathrm{~mol} .1^{-1}$ polyanion solutions. For example, in the presence of $0.1 \mathrm{~mol} .1^{-1}$ $\mathrm{NaCl}$, a precipitate appeared when $\mathrm{N}_{\mathrm{PC}} / \mathrm{N}_{\mathrm{PA}}=$ $0.12,0.22$ and 0.50 respectively for NaPLCA, NaPLCAI and NaPAA. In contrast, precipitation was observed at $\mathrm{N}_{\mathrm{PC}} / \mathrm{N}_{\mathrm{PA}}=0.72$ and 0.81 , respectively for NaPSS and NaPMA. Presumably, particle size and surface charge contributed to the differences, although correlation is not proved so far. For all polyanions other than PSS, there was a critical $\mathrm{NaCl}$ concentration above which solid did not appear anymore, $\mathrm{OD}_{520}$ remaining very low. This critical salt concentration depended on the nature of the polyelectrolyte (Table I). In contrast, PSS complexes precipitated even at $3 \mathrm{~mol} .1^{-1} \mathrm{NaCl}$ thus showing high stability, as already mentioned in literature for another polycation (Dautzenberg and Karibyants, 1999).

The influence of ionic strength on a nanodispersed IPEC prepared from a mixture of NaPAA $\left(1.0 .10^{-3}\right.$ mol. $1^{-1}$ ) with PDMAEMA, $\mathrm{HCl}$ at $\mathrm{N}_{\mathrm{PC}} / \mathrm{N}_{\mathrm{PA}}=0.50$ in de-ionized water was investigated in more detail. Three zones appeared on plots shown in Fig. 3. At low ionic strength (below $0.05 \mathrm{~mol} .1^{-1}$ ), the system exhibited very low viscosity. Under these conditions the complex was under the form of nanoparticles stabilized by anionic charges in excess. At higher ionic strength $\left(0.05<\mu<0.12 \mathrm{~mol} .1^{-1}\right)$ charge screening led to aggregation. The greater the ionic strength, the greater the turbidity and also the greater the viscosity, at least up

TABLE I Critical $\mathrm{NaCl}$ concentration (in mol.1 ${ }^{-1}$ ) above which complexes returned to solution

\begin{tabular}{lcccc}
\hline & $\mathrm{NaCl}$ & $\mathrm{Nal}$ & $\mathrm{NH}_{4} \mathrm{Br}$ & $\mathrm{Na}_{2} \mathrm{SO}_{4}$ \\
\hline PAA-PDMAEMA & 1.0 & 0.6 & 0.8 & 1.2 \\
PMA-PDMAEMA & 2.7 & 1.0 & 2.2 & $-*$ \\
PSS-PDMAEMA & $-*$ & 2.6 & $-*$ & $-*$ \\
\hline
\end{tabular}

* No re-dissolution could be observed before $3 \mathrm{~mol} . \mathrm{l}^{-1}$ salt concentration. 


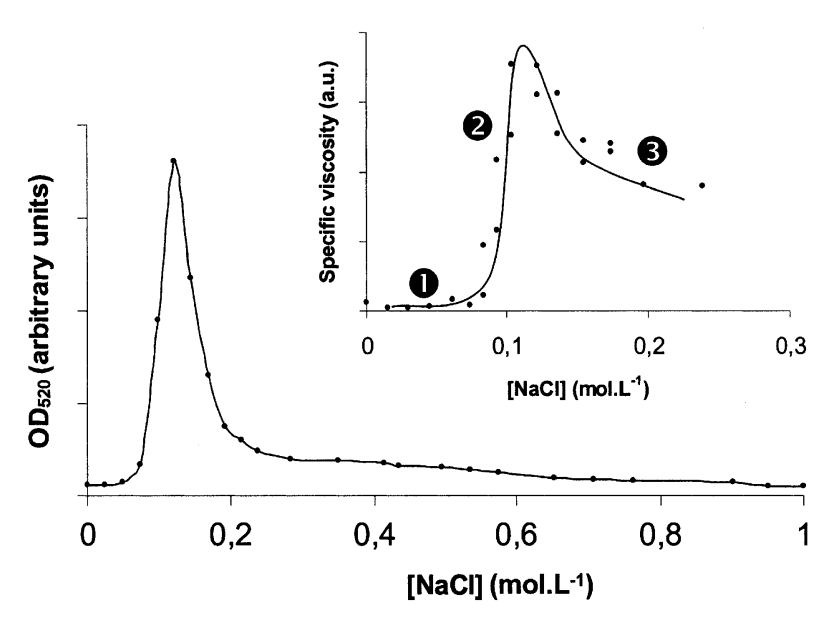

FIGURE 3 Variation of $\mathrm{OD}_{520}$ and specific viscosity for a NaPAA/PDMAEMA, $\mathrm{HCl}$ mixture at $\mathrm{N}_{\mathrm{PC}} / \mathrm{N}_{\mathrm{PA}}=0.50$ as a function of the salt concentration $\left([\mathrm{NaPAA}]=1 \cdot 0 \cdot 10^{-3} \mathrm{~mol} .1^{-1}\right)$.

to the maxima of turbidity and viscosity that occurred at the same ionic strength $\left(0.12 \mathrm{~mol} . \mathrm{l}^{-1}\right)$. The amount of precipitate at the maximum of viscosity corresponded to all polycation molecules combined with half of the polyanion molecules, a composition that agrees with the initial $\mathrm{N}_{\mathrm{PC}} / \mathrm{N}_{\mathrm{PA}}=0.5$ value, thus showing the respect of charge stoichiometry. The $50 \%$ excess of polyanion molecules remained in solution, as confirmed by NMR analysis. Higher salt concentration led to lower turbidity, transparency being observed for $\mathrm{NaCl}$ concentrations higher than $1 \mathrm{M}$.

The ionic strength at which precipitation was detected varied from one polyanion to the other and depended on the initial $\mathrm{N}_{\mathrm{PC}} / \mathrm{N}_{\mathrm{PA}}$ ratio. Qualitatively one can conclude that larger this ratio, the lower the salt concentrations required to observe macroscopic precipitation (Fig. 4). The trend might have dramatic consequences in the case of injections of polyelectrolytes or IPECs into blood where proteins and other polycharged species are present.

Complex Destabilization: Re-dissolution of STOICHIOMETRIC IPECS

All IPECs systems taken at charge stoichiometry (according to precipitate weighing and NMR analysis of the supernatants), except PSS-PDMAEMA, could be

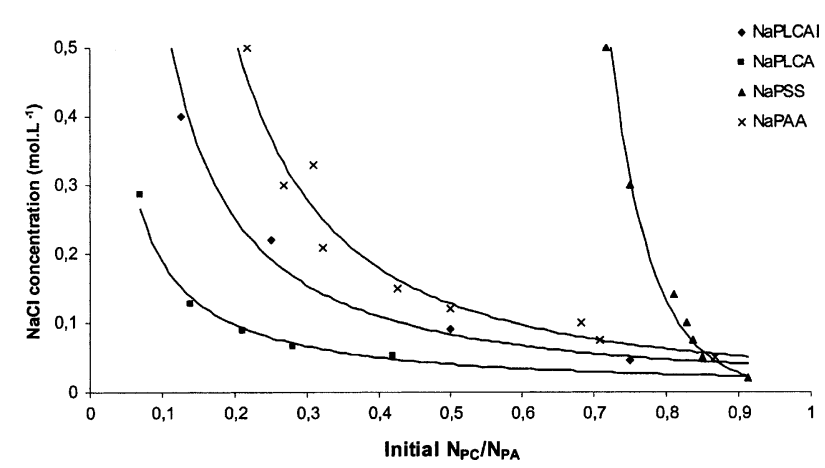

FIGURE 4 Variation of the $\mathrm{NaCl}$ concentration at which precipitation occurred as a function of the initial $\mathrm{N}_{\mathrm{PC}} / \mathrm{N}_{\mathrm{PA}}$ ratio for various polyanions $\left([\right.$ Polyanion $\left.]=1 \cdot 0 \cdot 10^{-3} \mathrm{~mol} .1^{-1}\right)$. dissolved at high $\mathrm{NaCl}$ concentrations. However, none of them could be destabilized in the presence of $0.15 \mathrm{M} \mathrm{NaCl}$ that mimicked the physiological ionic strength. The same experiments were also conducted with other sodium halides, which are normally not present in significant amounts in body fluids. The solubilizing effect depended on both the nature of the polyanion and the nature of the halide anion (Table I). The order of efficiency under comparable conditions was iodide $>$ bromide $>$ chloride. In no case dissolution at $0.15 \mathrm{M}$ was observed. It is worth noting that in body fluids, multivalent ions are present such as sulfate, phosphate and calcium that may affect complex formation and stability. The consequences were not investigated in this preliminary approach. It is worth noting that destabilization of IPECs can be a concern in the case of polyelectrolytes with low charge density or ionic strength-related acid or base strengths, as it is the case for biopolymers, occasionally.

\section{Under Conditions Aimed at Modelling Body Fluids $\left(\mathrm{pH}=7.4, \mathrm{~T}=37^{\circ} \mathrm{C}\right.$ and $\mu=0.15$ )}

At $\mathrm{pH}=7.4, T=37^{\circ} \mathrm{C}$ and $\mu=0.15$, the ionization states of polycarboxylic acid salts at $1.0 .10^{-2} \mathrm{~mol} .1^{-1}$ were comparable with a degree of ionization in the range of 0.9 (pKo $\sim 6.2$ in $0.15 \mathrm{M} \mathrm{NaCl}$ ). In contrast, NaPSS was totally charged in agreement with the stronger acidity of sulfonic acid groups. On addition of the polycation, $\mathrm{OD}_{520}$ increased progressively up to a critical $\mathrm{N}_{\mathrm{PC}} / \mathrm{N}_{\mathrm{PA}}$ value where the increase became dramatic in agreement with macroscopic precipitation, as already observed in the case of de-ionized water (Fig. 5). This critical $\mathrm{N}_{\mathrm{PC}} / \mathrm{N}_{\mathrm{PA}}$ value depended on the nature of the polyanion. For a given polymer concentration, it was much lower than in de-ionized water due to the screening of the charges by small ions. For NaPSS and NaPAA the critical values were 0.70 and about 0.02 , respectively. For NaPMA $\mathrm{OD}_{520}$ remained very low up to 0.56 . However, in this case, mixing at low $\mathrm{N}_{\mathrm{PC}} / \mathrm{N}_{\mathrm{PA}}$ ratios led to turbidity that turned clear after a few minutes, thus suggesting time-dependent two step complexation related to an anti-cooperative

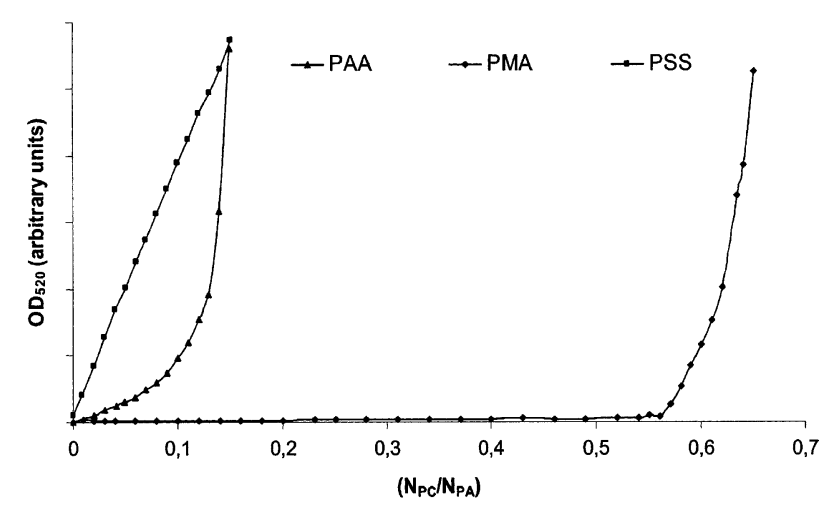

FIGURE 5 Variation of $\mathrm{OD}_{520}$ for the mixtures of PDMAEMA with various polyanions as a function of the $\mathrm{N}_{\mathrm{PC}} / \mathrm{N}_{\mathrm{PA}}$ ratio ([Polyanion] $=$ 1.0.10 $0^{-2} \mathrm{~mol}^{-1}$ ). 
mechanism, as suggested for the complexation of ionene molecules with NaPAA or NaPMA taken separately (Beyer, 1999). Presumably, the small NaPMA chains acted initially as a cross-linking agent to give a polyelectrolyte network insoluble in water. In the second stage, the IPEC rearranged to loop-like or completely bound NaPMA molecules only.

\section{Under Conditions aimed at Modelling Intracellular} Lysosomal Vesicles $\left(\mathrm{pH}=4.5, \mathrm{~T}=37^{\circ} \mathrm{C}\right.$ and $\left.\mu=0.15\right)$

Under these conditions and at low $4.5 \cdot 10^{-5} \mathrm{~mol} . \mathrm{1}^{-1}$ concentration, carboxylate groups of the polyanions were largely turned to unionized carboxylic acids. In contrast, PSS remained fully ionized. In the case of PAA and PSS the variations of $\mathrm{OD}_{520}$ were similar to those observed previously at neutral $\left(\mathrm{pH}=7.4, T=37^{\circ} \mathrm{C}\right.$ and $\left.\mu=0.15\right)$. The critical $\mathrm{N}_{\mathrm{PC}} / \mathrm{N}_{\mathrm{PA}}$ values from which $\mathrm{OD}_{520}$ increased dramatically were the same at $\mathrm{pH}=7.4$ and $\mathrm{pH}=4.5$. In the case of PMA, the values were totally different at $\mathrm{pH}=4.5 . \mathrm{OD}_{520}$ raised very slightly at low $\mathrm{N}_{\mathrm{PC}} / \mathrm{N}_{\mathrm{PA}}$ and then remained almost unchanged, a small number of rather large particles being visible. Normally PMA chains take on a compact coil conformation at low $\mathrm{pH}$ values, due to the contribution of pendent methyl groups to local hydrophobicity (Crescenzi et al., 1972). It is likely that the hydrophobic interactions that stabilize the PMA compact coil conformation contributed to the formation of rather big particles instead of the nanosized ones observed for the other more hydrophilic polyacids.

\section{Complexation between Two Polyanions and PDMAEMA, HCI}

In literature the competition between two polyanions for complex formation was generally conducted by adding the competing polyanion to a formed IPEC (Bekturov and Bimendina, 1981; Kabanov, 1985; Izumrudov et al., 1988; 1995). Given the fact that injection of a polyelectrolyte or of a polyelectrolytic complex in body fluids corresponds to introduction in a pool of charged polymers, we considered first the case where the polycation is added directly into solutions containing polyanions only. Indeed, in the case of preformed IPEC, the concurrent polyanion has to destabilize the existing complex and thus fight the short distance cooperative forces acting in addition to electrostatic interactions between the oppositely charged polyelectrolytes. In contrast, the second protocol is likely to be more favorable to selection since the polycation can basically have easier access to the preferred polyanion.

\section{In De-ionized Water}

The formation of IPEC when PDMAEMA, $\mathrm{HCl}$ was introduced in a solution of two different polyanions under their sodium salt forms was investigated as a function of ionic strength at $\mathrm{N}_{\mathrm{PC}} / \mathrm{N}_{\mathrm{PA}}<1$.
NaPMA and NaPSS at the same $3 \cdot 3 \cdot 10^{-3}$ mol.1 $1^{-1}$ concentration were selected as the two polyanions, the polycation being added so that $\mathrm{N}_{\mathrm{PC}} / \mathrm{N}_{\mathrm{PA}}=0.25$. After separation of the resulting two phases by centrifugation and filtration, the supernatant was freeze-dried and analyzed by NMR. The compounds issued from the solid and the solution were also analyzed by IR spectrometry.

The IR analysis was based on the fact that the stoichiometric PSS-PDMAEMA complex presented a band typical of sulfonate groups at $1030 \mathrm{~cm}^{-1}$, i.e. in a wavelength range where the stoichiometric PMA-PDMAEMA complex did not absorb (Fig. 6a). After normalization of the IR spectra of both the recovered precipitate and the stoichiometric PSS-PDMAEMA complex according to the $1730 \mathrm{~cm}^{-1}$ band, the PSS content in the precipitate was evaluated from the relative height of the $1030 \mathrm{~cm}^{-1}$ bands. Data showed a small significant excess of PSS $(60 \%)$ in the precipitate (Table II, first line).

NMR analysis of the supernatant was based on the resonances typical of NaPSS aromatic protons (6-8 ppm) and NaPMA $\mathrm{CH}_{3}$ and $\mathrm{CH}_{2}$ protons (1-3 ppm). Data showed predominance of the polycarboxylate, thus confirming the excess of PSS found in the precipitate (Table II, first line).

\section{In Salt-containing Water}

The presence of salt increased the selectivity in favor of the PSS proportion in the precipitate, that raised from $60 \%$ in de-ionized water to $90 \%$ in $0.5 \mathrm{M} \mathrm{NaCl}$ at similar $\mathrm{N}_{\mathrm{PC}} / \mathrm{N}_{\mathrm{PA}}=0.25$ (Fig. 7 and Table II). It is likely that this selectivity was related to the difference of pKa between the two polyanions, sulfonic acids being stronger acids than carboxylic ones. The presence of the salt increased the difference in agreement with the fact that a PSS-based complex was stable regardless of $\mathrm{NaCl}$ concentration whereas a PMA-based complex was more sensitive to destabilization in the presence of $\mathrm{NaCl}$, as shown previously.

\section{Action of a Polyanion on a Preformed Polyelectrolyte Complex (Exchange Reaction)}

A 1:1 complex between NaPAA and PDMAEMA, $\mathrm{HCl}$ was prepared in the absence and in the presence of salt at two concentrations, namely 0.1 and $0.5 \mathrm{~mol} . \mathrm{1}^{-1}$. A solution of NaPSS was added dropwise to the different systems under strong stirring, so that amounts of NaPAA and NaPSS be equivalent in terms of negative charges. One day later the mixtures were centrifuged. The supernatants were dialyzed against water and finally freeze-dried. The content of the precipitate in PSS was determined by NMR as described above. PSS contents of 0,3 and $41 \%$ were found by NMR for the precipitates recovered in the presence of $0,0.1$ and $0.5 \mathrm{M}$ salt, respectively. Sulfur elemental analysis gave similar results (Table III), the contents being then 2, 2 and 33\%, 
(a)

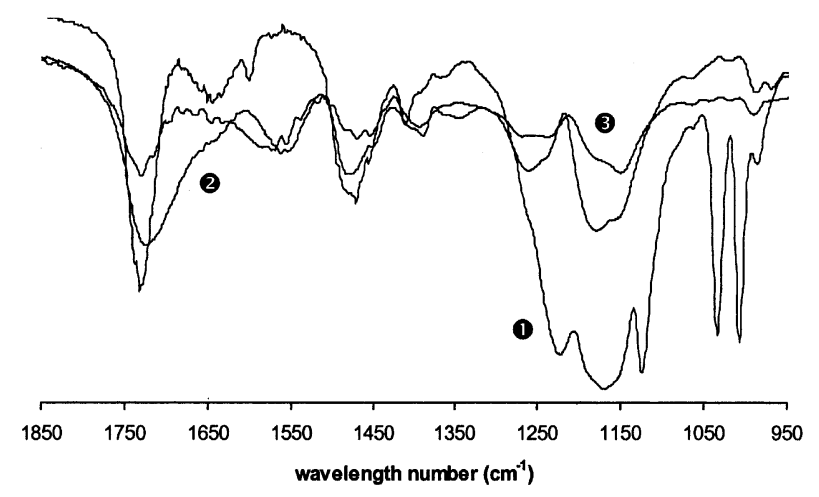

(b)

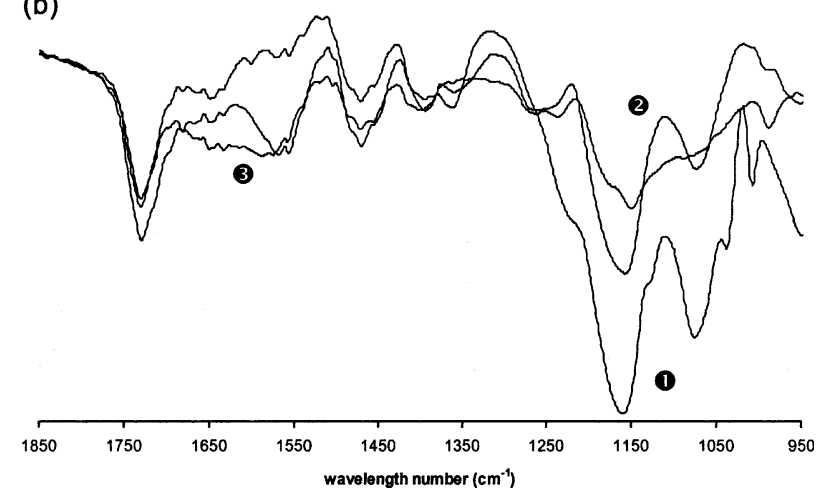

FIGURE 6 IR spectra of PSS-PDMAEMA (()), PMA-PDMAEMA (2) and PAA-PDMAEMA (3) stoichiometric complexes (Fig. 6a) and of NaPAA-NaPMA-NaPSS-PDMAEMA, $\mathrm{HCl}$ mixtures at $\mathrm{N}_{\mathrm{PC}} / \mathrm{N}_{\mathrm{PA}}=0.40(\boldsymbol{1}), \mathrm{N}_{\mathrm{PC}} / \mathrm{N}_{\mathrm{PA}}=0.67$ (2) and $\mathrm{N}_{\mathrm{PC}} / \mathrm{N}_{\mathrm{PA}}=1($ (3). $[\mathrm{NaPAA}]=$ $[\mathrm{NaPMA}]=[\mathrm{NaPSS}]=3 \cdot 3 \cdot 10^{-3} \mathrm{~mol} \cdot \mathrm{1}^{-1}$ (Fig. $6 \mathrm{~b}$ ).

respectively. The differences between low values, namely 0,2 and $3 \%$ were obviously not statistically significant. Under the selected conditions and despite the higher affinity of PSS to the polycation, the pre-formed PAAbased complexes remained stable upon addition of NaPSS provided the salt concentration remained low. This result fully agrees with data previously reported by Kabanov for the action of sodium polyvinylsulfonate on a pre-formed NaPMA-poly $(N$-ethyl- $N$-vinyl pyridinium) chloride complex, where the polysulfonate replaced the polycarboxylate in the complex (Kabanov et al., 1985).

\section{Under Conditions Aimed at Modelling Body Fluids $\left(p H=7.4, T=37^{\circ} \mathrm{C}\right.$ and $\left.\mu=0.15\right)$}

The variations of $\mathrm{OD}_{520}$ when a solution of PDMAEMA, $\mathrm{HCl}$ was mixed with an equimolar NaPAA/NaPMA solution

TABLE II Contents in PSS of the precipitates formed by mixtures of $\mathrm{NaPMA}+\mathrm{NaPSS}$ and PDMAEMA, $\mathrm{HCl}$ at various salt concentrations $\left(\mathrm{N}_{\mathrm{PC}} / \mathrm{N}_{\mathrm{PA}}=0.25\right)$

\begin{tabular}{lcc}
{$[\mathrm{NaCl}]\left(\mathrm{mol} \mathrm{l}^{-1}\right)$} & PSS content (IR data) & PSS content (NMR data) \\
\hline 0 & $60.0 \%$ & $60.8 \%$ \\
0.05 & $70.6 \%$ & $66.2 \%$ \\
0.1 & $74.6 \%$ & $74.7 \%$ \\
0.2 & $75.3 \%$ & $80.6 \%$ \\
0.5 & $89.6 \%$ & $87.7 \%$ \\
1 & - & $87.7 \%$ \\
\hline
\end{tabular}

$\left([\mathrm{NaPAA}]=[\mathrm{NaPMA}]=4 \cdot 0 \cdot 10^{-3} \mathrm{~mol} \cdot \mathrm{1}^{-1}\right)$ showed that, at low $\mathrm{N}_{\mathrm{PC}} / \mathrm{N}_{\mathrm{PA}}$ values, $\mathrm{OD}_{520}$ raised slowly up to a critical $\mathrm{N}_{\mathrm{PC}} / \mathrm{N}_{\mathrm{PA}}$ ratio above which it increased dramatically. Under the selected conditions, the critical value was 0.24 , i.e. a value comparable to that of NaPMA alone under similar conditions. NMR analysis of the supernatant obtained from the PAA/PMA-PDMAEMA system at $\mathrm{N}_{\mathrm{PC}} / \mathrm{N}_{\mathrm{PA}}=0.30$ showed the presence of polycationic molecules and consequently the presence of some nanosized complex in the supernatant. Therefore, it was not possible to evaluate the selectivity in this particular case.

In order to know whether a pre-complex can be destabilized by the addition of another polyanion under model physiological conditions, a NaPMA-PDMAEMA, $\mathrm{HCl}$ system at $\mathrm{N}_{\mathrm{PC}} / \mathrm{N}_{\mathrm{PA}}=0.2$ was submitted to the action of NaPSS. The solution was initially transparent at $520 \mathrm{~nm}$. The solution of NaPSS was added dropwise under strong stirring so that the equivalent ratio PSS/PDMAEMA be one at the end. The final mixture was then introduced in a quartz cell placed into a UV spectrophotometer. $\mathrm{OD}_{520}$ was measured as a function of time (Fig. 8). Progressive increase was observed and levelled off beyond $5 \mathrm{~h}$. The increase well agrees with exchange from PMA complex that was transparent at $\mathrm{N}_{\mathrm{PC}} / \mathrm{N}_{\mathrm{PA}}=0.2$ to PSS complex that was shown to yield turbid solutions under similar conditions (Fig. 5). After centrifugation, the precipitate and the supernatant were separated and analyzed by IR and NMR, respectively. According to IR, 

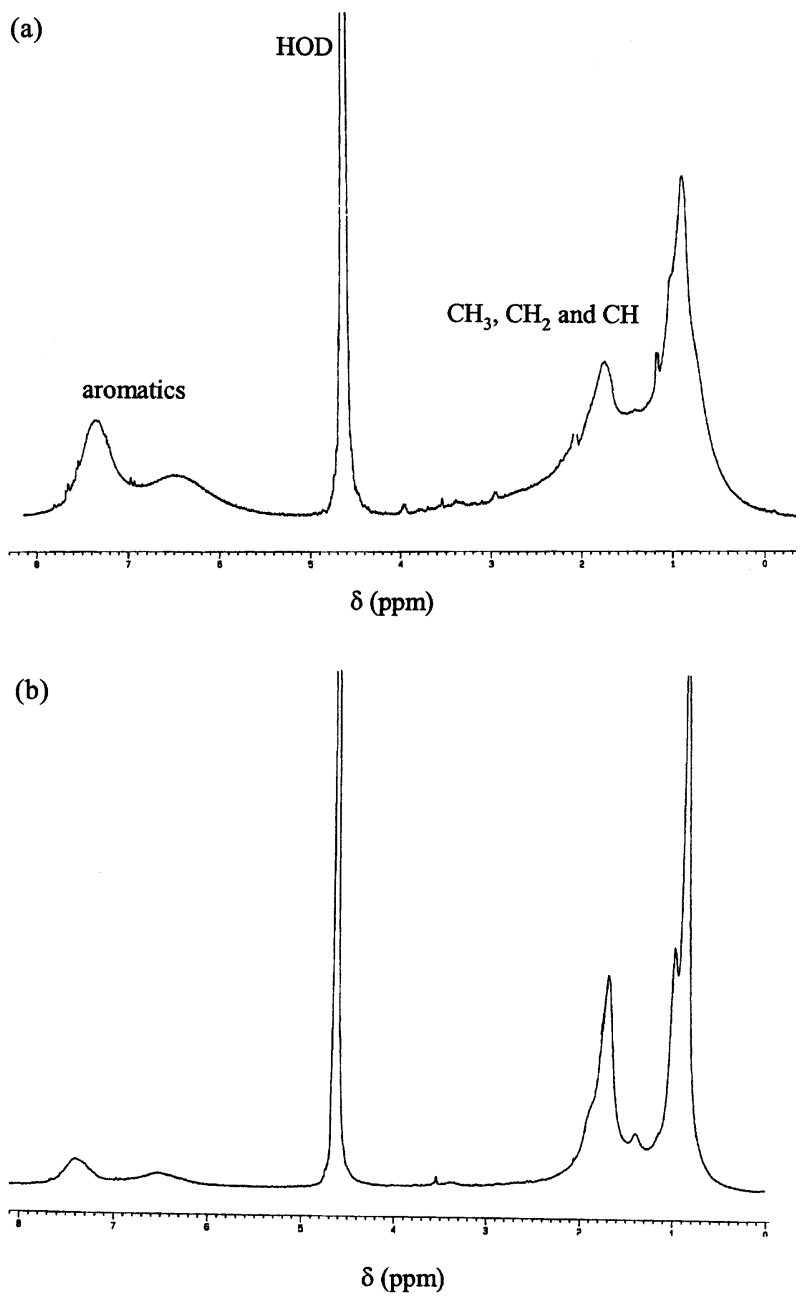

FIGURE $7{ }^{1} \mathrm{H}$ NMR of the filtrates of a mixture of NaPMA + NaPSS and PDMAEMA, $\mathrm{HCl}$ at $\mathrm{N}_{\mathrm{PC}} / \mathrm{N}_{\mathrm{PA}}=0.25$ in presence of salt (Fig. 7a: $[\mathrm{NaCl}]=0.05 \mathrm{~mol} .1^{-1}$ and Fig. $\left.7 \mathrm{~b}:[\mathrm{NaCl}]=0.5 \mathrm{~mol} .1^{-1}\right)$. [NaPMA] $=[\mathrm{NaPSS}]=3 \cdot 3 \cdot 10^{-3} \mathrm{~mol} \cdot 1^{-1}$.

the precipitate was composed of PSS and PDMAEMA only. In parallel NMR showed that only PMA was in the solution phase. Therefore, it was concluded that under conditions modelling physiological fluids, PSS was able to totally displace PMA from a complex with the polycation according to the following equation:

$$
\begin{aligned}
& \text { NaPMA in excess + PMA-PDMAEMA + NaCl } \\
& +\mathrm{NaPSS} \rightarrow \mathrm{NaPMA}+\mathrm{PSS}-\mathrm{PDMAEMA}+\mathrm{NaCl}
\end{aligned}
$$

TABLE III Contents in PSS of the precipitates when NaPSS was added to a preformed stoichiometric PAA-PDMAEMA complex at various salt concentrations

\begin{tabular}{lrr}
\hline & \multicolumn{2}{c}{ PSS content $(\%)$} \\
\cline { 2 - 3 }$[\mathrm{NaCl}]\left(\mathrm{mol} \mathrm{l}^{-1}\right)$ & $\mathrm{NMR}$ & $\mathrm{EA}$ \\
\hline 0 & 0 & 2 \\
0.1 & 3 & 2 \\
0.5 & 41 & 33 \\
\hline
\end{tabular}

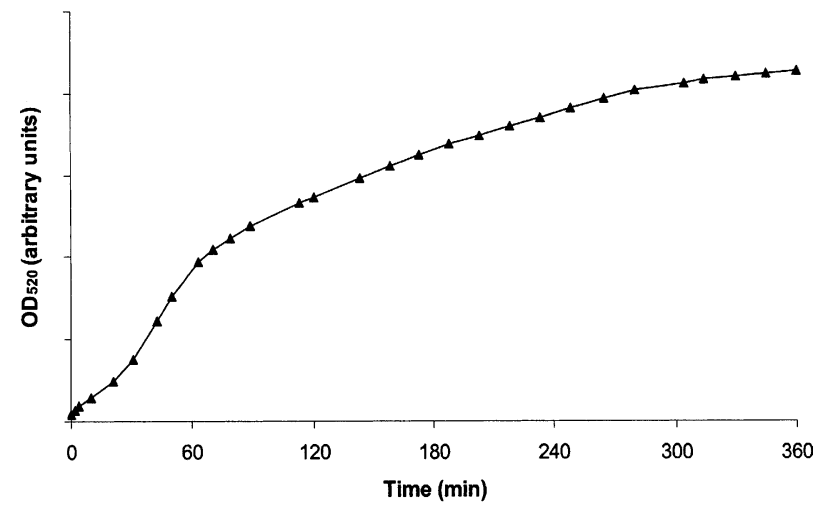

FIGURE 8 Variation of $\mathrm{OD}_{520}$ with time in the case of a NaPMA/PDMAEMA, $\mathrm{HCl}$ mixture at $\mathrm{N}_{\mathrm{PC}} / \mathrm{N}_{\mathrm{PA}}=0.2([\mathrm{NaPMA}]=$ 1.0.10 $\left.0^{-2} \mathrm{~mol} .1^{-1}\right)$.

\section{Under Conditions Aimed at Modelling Intracellular Lysosomal Vesicles $\left(\mathrm{pH}=4.5, \mathrm{~T}=37^{\circ} \mathrm{C}\right.$ and $\left.\mu=0.15\right)$}

The variations of $\mathrm{OD}_{520}$ when a solution of PDMAEMA, $\mathrm{HCl}$ was mixed with an equimolar PAA/PMA solution $\left([\mathrm{PAA}]=[\mathrm{PMA}]=2 \cdot 3 \cdot 10^{-5} \mathrm{~mol} . \mathrm{l}^{-1}\right) \mathrm{kept}$ at $\mathrm{pH}=4.5$ were found to be similar to those observed for a PMA solution under similar conditions. The precipitate could be dissolved at $\mathrm{pH}=2$ only. As it was found independently that destabilization of PMA IPECs required $\mathrm{pH}$ values as low as 2-2.5, whereas PAA IPECs were destabilized at $\mathrm{pH}=4-4.5$, the $\mathrm{pH}=2$ value suggested a strong predominance of PMA in the complex issued from the mixture of the polyanions. The source of this selectivity is still unclear.

The same experiment was carried out on an equimolar PMA/PSS solution $([\mathrm{PMA}]=[\mathrm{PSS}]=$ 2.3.10 ${ }^{-5} \mathrm{~mol}^{-1}$ ). The variation of $\mathrm{OD}_{520}$ was comparable to that observed in the case of PSS alone under similar conditions. The precipitate phase could only be dissolved above $\mathrm{pH}=9-9.5$, a feature which was found to be typical of PSS complexes. After the NMR analysis of the supernatant, only PSS was present in the solid phase.

From the behaviours of the two couple of polyanions, one could conclude that, at $\mathrm{pH}=4.5$, the order of increasing selectivity toward PDMAEMA is PSS $>$ PMA $>$ PAA, confirming the predominance of the sulfonate-containing polyanion found by Kabanov for other polyions (Kabanov et al., 1985).

\section{Complexation between Three Polyanions and PDMAEMA, HCl under Conditions Aimed at Modelling Body Fluids ( $\mathrm{pH}=7.4, T=37^{\circ} \mathrm{C}$ and $\boldsymbol{\mu}=\mathbf{0 . 1 5}$ )}

This work being aimed at investigating the behavior of a pool of polyanions in the presence of a polycation under fixed conditions mimicking physiological fluids, an equimolar mixture of NaPAA/NaPMA/NaPSS $\left([\mathrm{NaPAA}]=[\mathrm{NaPMA}]=[\mathrm{NaPSS}]=3 \cdot 3 \cdot 10^{-3} \mathrm{~mol} .1^{-1}\right)$ was considered to which PDMAEMA was added at various 


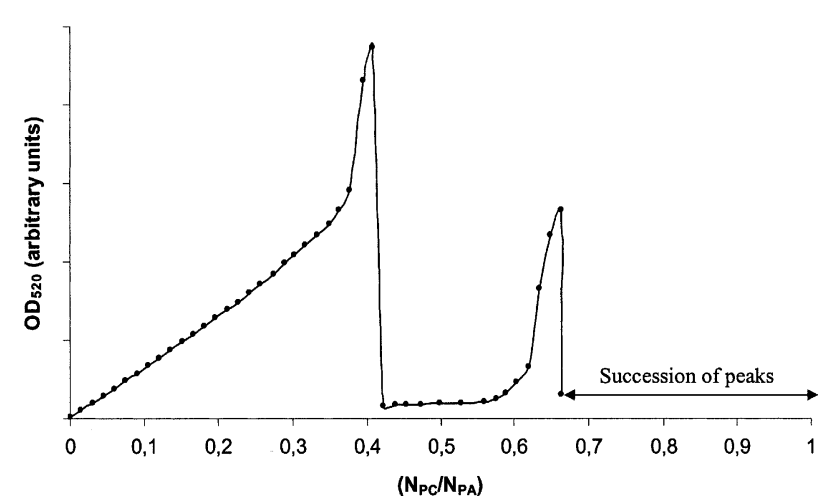

FIGURE 9 Evolution of $\mathrm{OD}_{520}$ for a mixture of $\mathrm{NaPAA}+$ $\mathrm{NaPMA}+\mathrm{NaPSS}$ and PDMAEMA, $\mathrm{HCl}$ as a function of the $\mathrm{N}_{\mathrm{PC}} / \mathrm{N}_{\mathrm{PA}}$ ratio $\left([\mathrm{NaPAA}]=[\mathrm{NaPMA}]=[\mathrm{NaPSS}]=3.3 \cdot 10^{-3} \mathrm{~mol} .1^{-1}\right)$.

$\mathrm{N}_{\mathrm{PC}} / \mathrm{N}_{\mathrm{PA}}$ ratios. Figure 9 shows the variation of $\mathrm{OD}_{520}$ with increasing $\mathrm{N}_{\mathrm{PC}} / \mathrm{N}_{\mathrm{PA}}$. At low $\mathrm{N}_{\mathrm{PC}} / \mathrm{N}_{\mathrm{PA}}$ values, $\mathrm{OD}_{520}$ increased progressively in the $0<\mathrm{N}_{\mathrm{PC}} / \mathrm{N}_{\mathrm{PA}}<0.4$ range. At $0.4, \mathrm{OD}_{520}$ decreased dramatically due to precipitation. The precipitate was separated by filtration and another aliquot of the polycation solution was added dropwise to the filtrate. The value of $\mathrm{OD}_{520}$ increased again up to a second critical value $\left(\mathrm{N}_{\mathrm{PC}} / \mathrm{N}_{\mathrm{PA}}=0.67\right)$ where it dropped again suddenly to yield a second fraction of complex by filtration. The stepwise addition of the polycation solution yielded precipitate fractions until the anion sites of the three polyanions were stoichiometrically complexed, thus explaining the series of peaks shown in Fig. 9. The IR spectrum of the precipitate obtained at $\mathrm{N}_{\mathrm{PC}} / \mathrm{N}_{\mathrm{PA}}=0.4$ exhibited the absorption bands typical of PSS, whereas IR spectra of the precipitates collected at higher $\mathrm{N}_{\mathrm{PC}} / \mathrm{N}_{\mathrm{PA}}$ did not (Fig. 6). The NMR spectra of the corresponding filtrates confirmed that PSS was complexed predominantly in the first precipitate that contained $75 \%$ of total PSS, a percentage that is comparable to that found for de-ionized water at $0.15 \mathrm{M}$ salt concentration $(70 \%)$ (Table II). These data reflect a rather high preferential affinity of our polycation to PSS, thus expending the finding of Kabanov to the case of three polyanions (Kabanov et al., 1985). It has not been possible to demonstrate selectivity between the two polycarboxylates so far, primarily because of signal overlapping and analytical difficulties. However, such selectivity is likely to occur, even if the difference of affinity for the polycation is smaller than between PSS and polycarboxylates.

As already stated, there has been little attention paid to the fact that physiological conditions imposed by body fluids drive charged polymer-living elements interactions and that interaction with natural polyelectrolytic systems present in living media can dramatically affect the behaviour and the biodisponibility of a polymeric drug carrier or a polycation-promoted gene transfecting system. It is evident that the phenomena reported by Ruponen (2001) are related to interaction and exchange between oppositely charged polyelectrolytic systems.

\section{CONCLUSION}

This work shows that preferential complexation is to be expected when several polysalts interact with the same polycation under conditions mimicking those imposed by physiological media and by physicochemical changes resulting from the post-injection dilution. For the selected polyelectrolytes and at low polymer concentrations, the complexes formed at low $\mathrm{N}_{\mathrm{PC}} / \mathrm{N}_{\mathrm{PA}}$ values were nanodispersed. The critical $\mathrm{N}_{\mathrm{PC}} / \mathrm{N}_{\mathrm{PA}}$ ratio from which aggregation and then precipitation occurred depended on the type of the polyanion and on the ionic strength. Selectivity in favor of PSS was observed when the polycation was added to a mixture of two or three polyanions, thus expending the finding reported in literature for pairs of polyanions under slightly different conditions (Kabanov et al., 1985). It has not been possible to distinguish PAA from PMA polymers when these polymers were engaged simultaneously in a complex at $\mathrm{pH}=7.4$. Anyhow, from data collected at $\mathrm{pH}=4.5$, one can conclude at least qualitatively that selectivity is likely to occur also between the polycarboxylates regardless of the $\mathrm{pH}$. The fact that NaPSS could not destabilize a preformed stoichiometric PAA-polycation complex in pure water suggested that short range non electrostatic interactions can play an important role in the IPEC stability under the selected particular conditions, the presence of hydrophilic substituent like $\mathrm{OH}$ groups as well.

If confronted to the cases of complexes involved in gene transfection or polyelectrolyte-based drug delivery or targeting in the blood flow, our data suggest that injecting a polyelectrolyte complex or a more or less charged polymeric drug carrier is likely to perturb locally the equilibria between polyelectrolytic cells and biopolymers present in human tissues and body fluids. Our approach was based on a maximum of three polyanions. In the next stage, a larger library of polyelectrolytes will be considered in order to study under which conditions a given polycation can select some of the members by selective complexation under specific environmental conditions as it is in biological fluids, especially in blood. The strategy is also being applied to biopolymers mimicking gene-polycation condensed systems.

\section{References}

Behr, J.P. (1994) "Gene transfer with synthetic cationic amphiphiles: prospects for gene therapy", Bioconjug. Chem. 5, 382-389.

Bekturov, E.A. and Bimendina, L.A. (1981) "Interpolymer complexes", Adv. Polym. Sci. 41, 99-147.

Beyer, P. and Nordmeier, E. (1999) "Ultracentrifugation, viscosity, $\mathrm{pH}$ and dynamic light scattering studies of the complexation of ionene with poly(acrylic acid) and poly(methacrylic acid)", Eur. Polym. J. 35, $1351-1365$.

Blessing, T., Malgorzata, K., Holzhauser, R., Kircheis, R. and Wagner, E. (2001) "Different strategies for formation of PEGylated EGFconjugated PEI/DNA complexes for targeted gene delivery", Bioconjug. Chem. 12, 529-537.

Boustta, M., Huguet, J. and Vert, M. (1991) "New functional polyamides derived from citric acid and L-lysine: synthesis and characterization, Makromol", Chem. Macromol. Symp. 47, 345-355. 
Bovey, F.A. (1963) J. Polym. Sci. 1, 843.

Crescenzi, V., Quadrifoglio, F and Delben, F. (1972) "Calorimetric investigation of Poly(methacrylic acid) and Poly(acrylic acid) in aqueous solution", J. Polym. Sci. Part A-2 10, 357-368.

Dautzenberg, H. and Karibyants, N. (1999) "Polyelectrolyte complex formation in highly aggregating systems. Effect of salt: response to subsequent addition of $\mathrm{NaCl}$ ", Macromol. Chem. Phys. 200, $118-125$.

Fuoss, R.M. and Sadek, H. (1949) "Mutual interaction of polyelectrolytes", Science 110, 552-573.

Hara, M. and Nakajima, A. (1978) "Formation of the polyelectrolyte complex of heparin with aminoacetalized poly(vinyl alcohol)", Polym. J. 10, 37-44.

Izumrudov, V.A., Bronich, T.K., Saburova, O.S., Zezin, A.B. and Kabanov, V.A. (1988) "The influence of chain length of a competitive polyanion and nature of monovalent counterions on the direction of the substitution reaction of polyelectrolyte complexes", Macromol. Chem. Rapid Commun. 9(1), 7-12.

Izumrudov, V.A., Kargov, S.I., Zhiryakova, M.V., Zezin, A.B. and Kabanov, V.A. (1995) "Competitive reactions in solutions of DNA and water-soluble interpolyelectrolyte complexes", Biopolymers 35, $523-531$.

Kabanov, V.A. and Zezin, A.B. (1984) "Soluble interpolymeric complexes as a new class of synthetic polyelectrolytes", Pure Appl. Chem. 56, 343-354.

Kabanov, V.A., Zezin, A.B., Izumrudov, V.A., Bronich, T.K. and Bakeev, K.N. (1985) "Cooperative interpolyelectrolyte reactions", Makromol. Chem. 13(Suppl.), 137-155.

Kabanov, V.A. (1994) "Basic properties of soluble interpolyelectrolyte complexes applied to bioengineering and cell transformation", In: Dubin, ed, Macromolecular Complexes in Chemistry and Biology (Springer-Verlag, Berlin) chapter 10, p 151.

Kabanov, A.V. and Kabanov, V.A. (1995) "DNA complexes with polycations for the delivery of genetic material into cells", Bioconjug. Chem. 6(1), 7-20.

Kossel, A. (1896) J. Physiol. Chem. 22, 178-183.

Kötz, J., Köpke, H., Schmidt-Naake, G. and Vogl, O. (1996) "Polyanionpolycation complex formation as a function of the position of the functional groups", Polymer 37(13), 2775-2781.
Michaels, A.S. and Miekka, R.G. (1961) "Polycation-polyanion complexes. Preparation and properties of poly(vinylbenzyltriméthyl-ammonium) polystyrene sulfonate", J. Phys. Chem. 65, 1765.

Morawetz, H. (1965) Macromolecules in Solution (Interscience Publishers, New York).

Moreau, E., Chapon, P., Vert, M. and Domurado, D. (2000a) "Influence of desialylation on the interaction of red blood cells with a hemotoxic partly quaternized tertiary polyamine", J. Bioact. Compat. Polym. 15, 447-467.

Moreau, E., Ferrari, I., Drochon, A., Chapon, P., Vert, M. and Domurado, D. (2000b) "Interactions between red blood cells and a lethal, partly quaternized tertiary polyamine", J. Control. Release 64, $115-128$.

Moreau, E., Domurado, M., Chapon, P., Vert, M. and Domurado, D. (2002) "Biocompatibility of polycations: in vitro agglutination and lysis of red blood cells and in vivo toxicity", J. Drug Target 10, $161-173$.

Nakajima, J. (1980) "Formation of polyelectrolyte complexes", J. Macromol. Sci. Part B 17, 715-721.

Philipp, B., Dautzenberg, H., Linow, K.J., Koetz, J. and Dawydoff, W. (1989) "Polyelectrolyte complexes. Recent developments and open problems", Prog. Polym. Sci. 14, 91-172.

Rembaum, A. and Sélégny, E. (1975) Polyelectrolytes and their Applications (D. Reidel Publishing Company, Dordrecht-Holland), pp 131-230.

Ruponen, M., Rönkkö, S., Honkakoski, S., Pelkonen, J., Tammi, M. and Urtti, A. (2001) "Extracellular glycosaminoglycans modify cellular trafficking of lipoplexes and polyplexes", J. Biol. Chem. 276(36), $33875-33880$.

Tsuchida, E. (1980) "Formation of interpolymer complexes", J. Macromol. Sci. Part B 17(4), 683-714.

Tsuchida, E. and Abe, K. (1982) "Interactions between macromolecules in solution and intermacromolecular complexes", Adv. Polym. Sci. 45, $1-119$.

Tsuchida, E. (1994) "Formation of polyelectrolyte complexes and their structures", J. Macromol. Sci. Part A 31(1), 1-15.

Vert, M. (1986) "Polyvalent polymeric drug carriers", Crit. Rev. Ther. Drug Carrier Syst. 2(3), 291-327. 


\section{Dear Author,}

During the preparation of your manuscript for typesetting some questions have arisen. These are listed below. Please check your typeset proof carefully and mark any corrections in the margin of the proof or compile them as a separate list. This form should then be returned with your marked proof/list of corrections to Alden Multimedia.

\section{Disk use}

In some instances we may be unable to process the electronic file of your article and/or artwork. In that case we have, for efficiency reasons, proceeded by using the hard copy of your manuscript. If this is the case the reasons are indicated below:

$\square$ Disk damaged $\square$ Incompatible file format $\quad \square$ LaTeX file for non-LaTeX journal

$\square$ Virus infected $\square$ Discrepancies between electronic file and (peer-reviewed, therefore definitive) hard copy.

$\square$ Other:

We have proceeded as follows:
Manuscript scanned
Manuscript keyed in
Artwork scanned
Files only partly used (parts processed differently:

\section{Bibliography}

If discrepancies were noted between the literature list and the text references, the following may apply:

The references listed below were noted in the text but appear to be missing from your literature list. Please complete the list or remove the references from the text.

Uncited references: This section comprises references which occur in the reference list but not in the body of the text. Please position each reference in the text or, alternatively, delete it. Any reference not dealt with will be retained in this section.

\begin{tabular}{|l|l|l|}
\hline $\begin{array}{l}\text { Manuscript } \\
\text { page/line }\end{array}$ & Details required & Author's Response \\
\hline & Kindly check th insertd the running title. & \\
\hline
\end{tabular}

